DOI: $10.14451 / 1.184 .82$

\title{
ИНОСТРАННЫЕ ИНВЕСТИЦИИ В СТРОИТЕЛЬНОЙ СФЕРЕ РОССИИ И КИТАЯ
}

\author{
(C) 2020 Карлик Александр Евсеевич \\ доктор экономических наук, профессор, заведующий кафедрой экономики \\ и управления предприятиями и производственными комплексами \\ Санкт-Петербургский государственный экономический университет, Россия, Санкт-Петербург \\ E-mail: Karlik1@mail.ru \\ (c) 2020 Юй Цзинчэнь \\ аспирант, кафедра экономики и управления предприятиями и производственными комплексами \\ Санкт-Петербургский государственный экономический университет, Россия, Санкт-Петербург \\ E-mail: may_9171@mail.ru
}

В статье определены особенности прямых иностранных инвестиций в строительной сфере России и Китая. Проанализирована динамика и структура прямых иностранных инвестиций в строительной сфере России и Китая, проведено их сравнение и сделаны соответствующие выводы

Ключевые слова: прямые иностранные инвестиции, строительство, динамика, структура

Повышение эффективности функционирования национальных экономик непосредственно связано с процессом привлечения иностранных инвестиций, что объясняется рядом хорошо известных причин. Действительно, во многих случаях иностранные инвестиции могут послужить целям ускоренного экономического развития, роста конкурентоспособности, поскольку основной целью является не столько привлечение иностранных инвестиций в денежном эквиваленте, а скорее, технические и технологические решения, которые принесут потенциальные инвесторы. Последнее же является основой повышения конкурентоспособности отечественного производства, ускорения экономического и технологического прогресса, расширения экспортного потенциала страны. Государственное регулирование инвестиций в форме прямого капитала осуществляется по двум векторам: контроль за поступлением иностранных инвестиций (оценка масштабов, распределение по отраслям и территориям, формы) и контроль за импортом капитала. Стоит выделить универсальный комплекс мер стимулирования, используемый в мировой практике для привлечения прямого иностранного капитала: налоговые меры (предоставление инвестору налоговых льгот или “налоговых каникул”, освобождение его от уплаты таможенных пошлин или сборов); финансовые меры (субсидии от государства, гранты, льготные кредиты и займы); создание благоприятного инвестиционного климата, создание особых экономических зон, формирование современной законодательной базы и соответствующей инфраструктуры, необходимой для осуществления инвестиционной деятельности.

Эти стимулирующие меры объединяются и используются во многих странах для привлечения иностранного капитала. В последние десятилетия в странах с разным уровнем социально-экономического развития сложились следующие особенности финансирование инвестиций. Страны с высоким уровнем социальноэкономического развития делают упор на финансовые меры стимулирования инвестиций. Развивающиеся страны отдают предпочтение налоговым мерам в связи с тем, что они не располагают необходимыми финансовыми ресурсами для увеличения инвестиций. Второй особенностью является наметившаяся устойчивая тенденция к широкому использованию нефинансовых стимулов, например, создание особых экономических зон с привлечением финансовых инвестиций, упрощение административных процедур открытия и ведения бизнеса для иностранных инвесторов [12].

Проблема современности, учитывая такие глобальные факторы как эпидемия коронавируса, тотальное падение цен на нефть и падение практически всех рыночных индексов состоит в том, что все эти факторы негативно влияют на инвестирование в реальный капитал, что ставит под сомнение дальнейший (в перспективе) рост реального сектора экономики Рассмотрим динамику прямых иностранных инвестиций в России и Китае. В 2009 году в связи с мировым финансовым кризисом, объем прямых иностранных ин- 
вестиций в Россию значительно снизился.

Хотя 2010 г. демонстрирует рост инвестиций, в 2011-2012 гг. снова наблюдается их резкое снижение. Аналогичное снижение произошло и в 2016-2017 гг., когда была продемонстрирована динамика роста, прервавшаяся падением в 2018 году и с некоторым ростом в 2019 году (рис. 1). При этом в 2018 году был зафиксирован наибольший с 1997 года отток прямых иностранных инвестиций из капитала российских компаний (6,46 млрд. долл.) [3].

Структура прямых иностранных инвестиций в Россию (основные инвесторы) показывает, что традиционно ими являются Кипр, Люксембург,
Нидерланды, Багамские острова, т.е. именно офшоры, что позволяет считать инвестируемые в российскую экономику капиталы ранее выведенными из российской экономики.

Анализ влияния инвестиций из Китая на строительную сферу российской экономики, следует рассмотреть, в первую очередь, с позиций привлечения и вложения прямых инвестиций. Если рассматривать динамику иностранных инвестиций в Китай за анализируемый период, мы видим, что динамика привлечения инвестиций за 1995-2018 гг. сохраняет позитивный характер (рис 2), хотя и с падением темпов роста в последние годы.

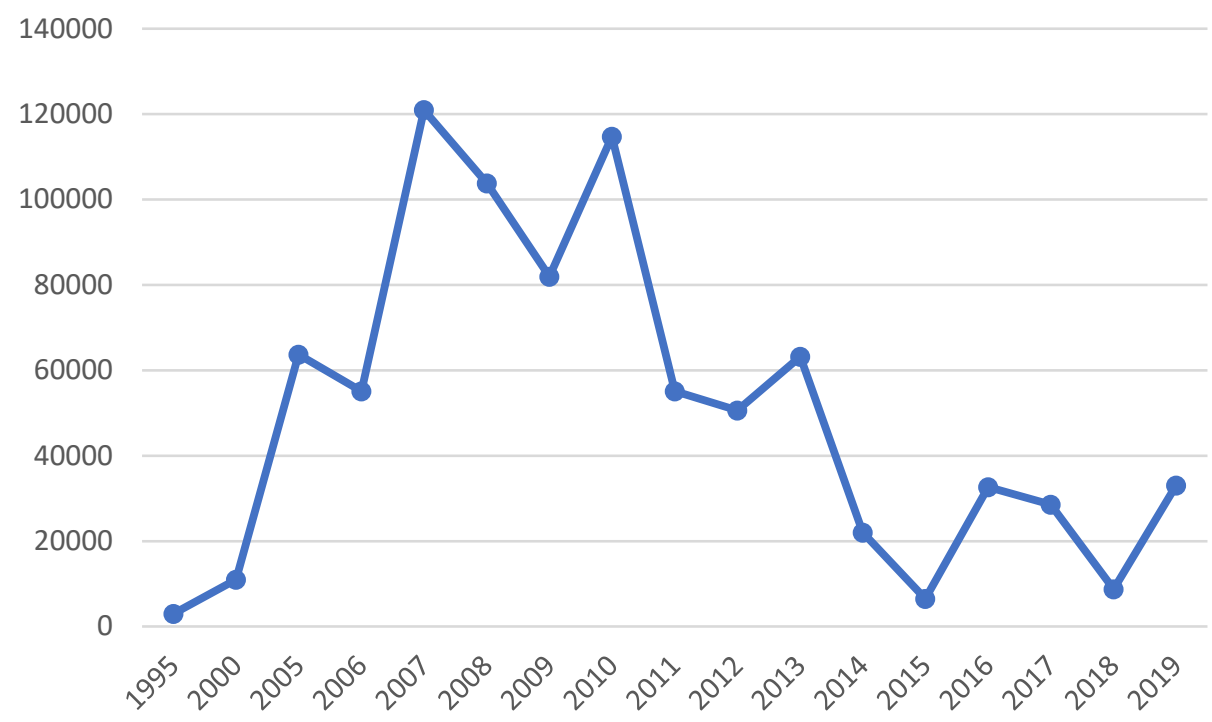

Puc. 1. Динамика прямых иностранных инвестиций в экономику России, млн.долл. [1, 3] Источник: Российский статистический ежегодник (2011, 2016, 2019 гг.).

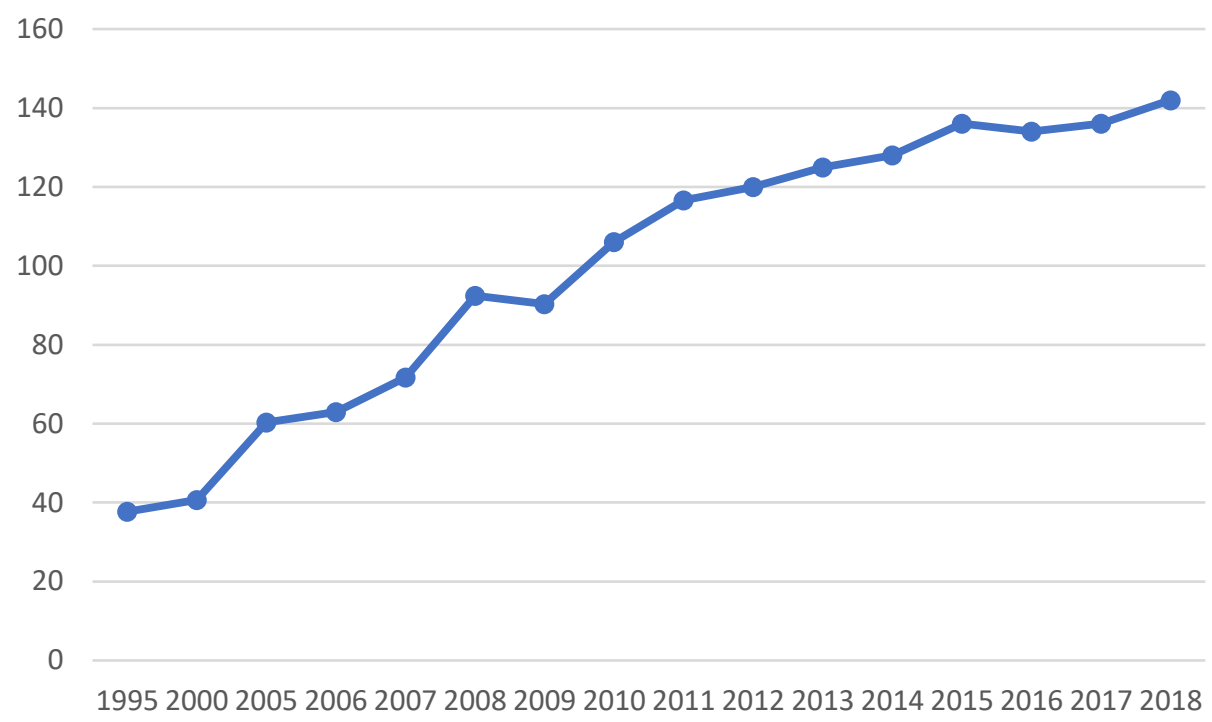

Рис. 2. Динамика привлечения прямых иностранных инвестиций в Китай за 1995-2018 гг., млрд. долл. США 
Следовательно, если сравнивать динамику прямых иностранных инвестиций в России и Китае, можно сделать вывод, что в Россия не всегда воспринимается как надежный реципиент инвестиций, но положение страны стабильно и не рискованно для вложений, что еще раз было подтверждено резким ростом иностранных инвестиций в 2019 году (учитывая различные негативные факторы - политические коллизии, информационную войну и др.).

Если рассматривать строительную сферу Китая, то в четвертом квартале 2017 года строительная активность в Китае выросла на 6,1\%, подталкивая рост за год до 4,5\%. Это ниже двузначного роста, которым этот сектор характеризовался ранее. Если рассматривать прогнозируемые темпы роста строительства Китая (рис. 3), то предполагается замедление роста.

Однако прогнозирование спроса на строительную продукцию в Китае является сложной задачей, поскольку экономическая система построена на достаточно сильном государственном регулировании в целях стимулирования или охлаждения экономики в соответствующих ситуациях. Если экономический рост замедлится, правительство может использовать инвестиции в строительство в качестве инструмента увеличения темпов роста, что может вызвать еще один всплеск активности. В данном случае рост инвестиций в строительство приобретает мультипликативный характер, поскольку за повышением деловой активности в строительстве, то же самое происходит в металлургии, производстве строительных машин и др. И наоборот, если экономика перегреется, и инфляция начнет расти, правительство может принять целевые меры в секторе недвижимости и строительства по замедлению роста, в частности в виде снижения инвестиционной активности [10].

Инвестиции в крупномасштабные инфраструктурные проекты были ключевой частью стратегии китайского правительства по стимулированию роста. Отчасти именно по этой причине ожидается, что рост останется на относительно низком уровне в $4,5 \%$.

Предполагается, что строительная отрасль должна быть приоритетной в определенном периоде, несмотря на серьезные ограничения, связанные с обеспечением человеческими ресурсами [13]. Более того, строительная отрасль должна помочь экономике страны восстановиться в посткризисный период, а также способствовать смягчению социальных проблем.

Должны быть найдены пути, чтобы воспользоваться преимуществами особенностей строительства, предлагающими уникальные возможности. Во-первых, строительная отрасль должна эффективно играть свою роль в экономике, реализуя потенциал создания рабочих мест во всех регионах страны, а также стимулирования деловой активности в других секторах экономики. Новые стратегии необходимы, чтобы сделать это возможным. Во-вторых, именно строительство лежит в основе развития инфраструктуры. Инвестиции в строительство, одновременно играющие стимулирующую роль в развитии экономики и расширяющие основы частной собственности населения вносят свой вклад в

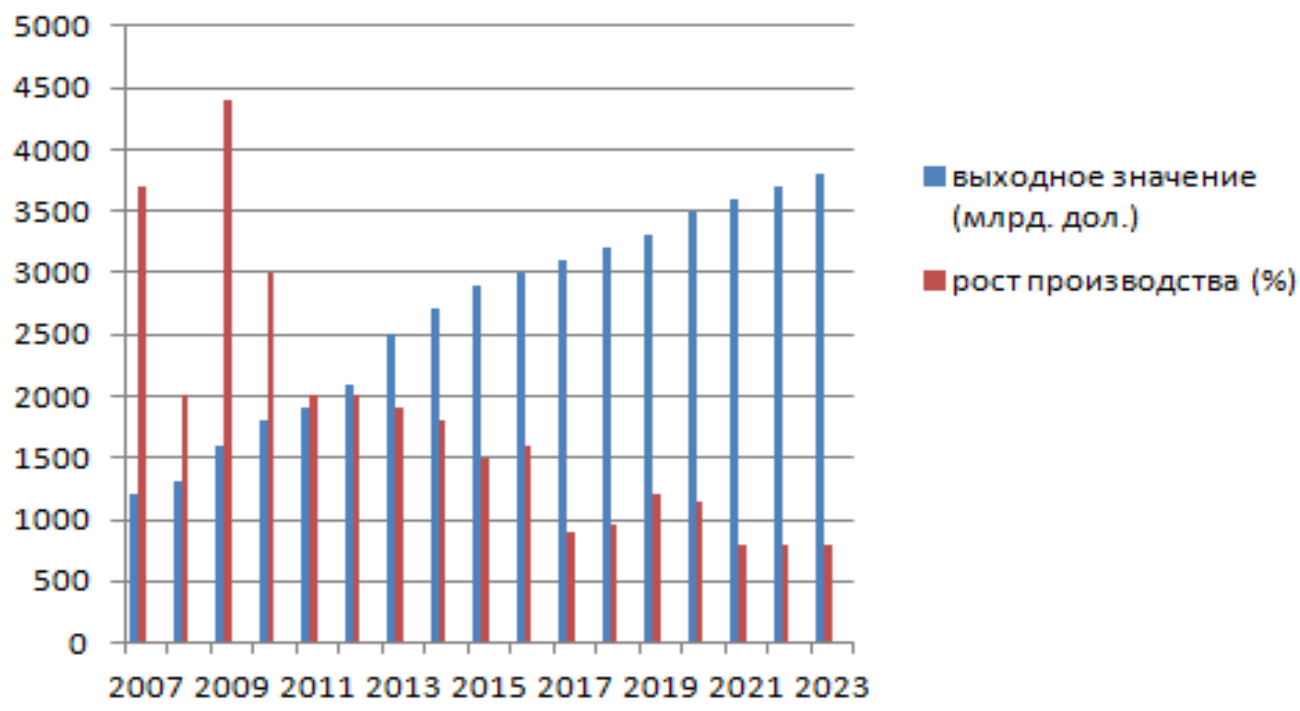

Рис. 3. Прогнозируемые темпы роста строительства Китая [11] 
крупные проекты развития.

Основными формами прямых иностранных инвестиций считаются создание совместных и дочерних предприятий и компаний, открытие собственных филиалов и проведение сделок M\&A. Значение иностранных инвестиций в экономике современных государств возрастает, поэтому они требуют регулирования и контроля на международном и национальном уровнях. Таким образом, необходимо использовать системный подход для понимания государственного регулирования прямых иностранных инвестиций с учетом общих интересов принимающего государства и прямого иностранного инвестора. Необходимость такого государственного регулирования связана с возможными рисками и негативными последствиями неконтролируемого притока средств финансирования в экономику страны-реципиента, а также с разнонаправленными интересами иностранного инвестора и государства-реципиента капитала.

Анализ китайских инвестиций в экономику и строительство Российской Федерации, позволяет отметить следующее. КНР обладает значительным инвестиционным потенциалом и технологиями для реализации долгосрочных инвестиций в сферу непосредственно строительства, а также инфраструктурных проектов. Китай никогда не был основным инвестором в России и не стал им даже на фоне падения западных инвестиций в Россию [4]. Тем не менее, еще в 2012 году ряд китайских строительных компаний, в т.ч. China State Construction Engineering Corporation (CSCEC), начали вести переговоры об инвестировании в строительство, в первую очередь, жилья в Российской Федерации. В качестве примера можно привести проект «Балтийская жемчужина» в Санкт-Петербурге. Начало реализации проекта приходится на 2004 год, когда в рамках побратимских отношений Шанхая и Санкт-Петербурга Шанхайская индустриально-инвестиционная группа получила в долгосрочную аренду около 200 га земли, где было возведено свыше 1 млн. квадратных метров жилой недвижимости. ЗАО «Балтийская жемчужина» - дочерняя структура Шанхайской Заграничной Объединенной Инвестиционной Компании, учредителями которой выступают 7 наиболее крупных корпораций Шанхая. Следует отметить, что КНР активно инвестирует в строительство и связанные с ним отрасли. Так, например «насосы, энерготехнические установки, подъемные механизмы и другая строительная техника Китая находит широкое распространение, например, в московском высотном строительстве». Некоторые станции московского метро строятся китайскими компаниями с привлечением китайского оборудования и рабочих Китая [8]. Одна из проблем исследований состоит в том, что точный учет китайских инвестиций в Россию практически невозможен. Статистика Центробанка России учитывает только инвестиции, напрямую пришедшие от китайских граждан и с территории КНР, в то время как зарубежные инвесторы (в том числе и китайские) осуществляют этот процесс через офшорные юрисдикции (практически это 50\% всех прямых иностранных инвестиций в Россию) или от имени компаний с неясными владельцами. Тем не менее вполне можно оценить, растут инвестиции или падают. Так на начало 2015 г. инвестиции Китая в РФ составили 2,76 млрд. долл. на начало 2018-4,2 млрд. долл. и на ноябрь 2018-2,99 млрд. долл. [2] Все представленное выше, говорит о том, что потенциал инвестирования Китаем российских (в том числе и строительных) проектов, находится, практически на достаточно низком уровне. Соответственно, России следует некоторым образом трансформировать политику привлечения инвестиций в важные для нее отрасли, в том числе строительство, с учетом требований инвесторов к улучшению инвестиционного климата, и выстраивания приоритетов требований к самим инвесторам. При этом же, конечно, необходимо расширение системы государственных гарантий структурообразующих инвестиций.

\section{Библиографический список}

1. В обход санкций. Зачем американцы вкладывают деньги в Россию? https://www.gazeta.ru/ business/2019/06/06/12397843.shtml.

2. Дружба на расстоянии руки. «Коммерсантъ» 31 мая 2019 года https://www.kommersant.ru/doc/3984186.

3. Иностранные инвестиции в России бьют рекорды. Финансовая газета, 21 марта 2020 г. https://fingazeta.ru/ ekonomika/mirovaya_ekonomika/459956/. 
4. мусина A. Eurasianet (США): Китай масштабно инвестирует по всему миру, но выводит деньги из России. https://inosmi.ru/economic/20191022/246079655.html

5. Российский статистический ежегодник. 2011: Стат.сб./Росстат.-P76 М., 2011.

6. Российский статистический ежегодник. 2016: Стат.сб./Росстат.-Р76 М., 2016

7. Российский статистический ежегодник. 2019: Стат.сб./Росстат.- Р76 М., 2019.

8. Рычагов М. Поднебесная экспансия. Китайцы инвестируют миллиарды в российский бизнес. https://www. forbes.ru/biznes/368233-podnebesnaya-ekspansiya-kitaycy-investiruyut-milliardy-v-rossiyskiy-biznes

9. Торговая экономика. https://tradingeconomics.com/russia/foreign-direct-investment

10. China's construction market growth to slow. - https://www.khl.com/international-construction/chinasconstruction-market-growth-to-slow/137183.article.

11. GlobalData. https://www.globaldata.com/global-construction-output-growth-to-reach-3-4-in-2019-saysglobaldata/

12. Gulnaz M. Galeeva, Elena P. Fazlieva, Adel A. Daryakin, Elena N. Zagladina. Foreign Direct Investments: Structure and Dynamics in Russia.- http://helix.dnares.in/2018/02/02/foreign-direct-investments-structure-and-dynamicsin-russia/

13. Ofori, $G$ (1993) Research in construction industry development at the crossroads. Construction Management and Economics, 11, 175-185.

14. Statista. Статистический портал [Электронный ресурс].- Режим доступа: https://knoema.ru/atlas/embed/Kитай/topics/Экономика/Платежный-баланс-Счет-операций-с-капиталом-и-финансовыми инструментами/ Прямые-иностранные-инвестиции-в-текущих-ценах-долл-США 